\title{
Evaluation of the Efficacy of Saline Infusion Sonohysterography in Patients with Postmenopausal Bleeding
}

\author{
Asha N Gokhale ${ }^{1}$, Sushma Surve ${ }^{2}$, Akriti Agarwal ${ }^{3}$
}

\begin{abstract}
Objective: To evaluate the efficacy of saline infusion sonohysterography as a primary screening tool in cases of postmenopausal bleeding and correlate the results with the findings of histopathological examination.

Materials and methods: This prospective observational study involved 34 postmenopausal patients with postmenopausal bleeding who attended the OPD of Obstetrics and Gynaecology at Deenanath Mangeshkar Hospital over a period of 4 years and were advised saline infusion sonohysterography (SIS). All women underwent transvaginal sonography (TVS) and saline infusion sonohysterography (SIS) followed by histopathological examination. The sensitivity, specificity, PPV, and NPV for TVS and SIS were analyzed using the HPE report as a gold standard. The advantages and limitations of the screening test were evaluated.

Results: The most common abnormalities detected on SIS were thickened endometrium seen in 13 cases (38.2\%), followed by polyps ( 11 cases, $32.4 \%$ ), thin endometrium ( 6 cases, $17.6 \%$ ), submucous fibroids ( 3 cases, $8.8 \%$ ), and undetermined ( 1 case, $2.9 \%$ ) among our study population with a mean age of $52 \pm 7.4$ years. Diagnostic accuracy of SIS in identifying patients with intrauterine abnormalities was $91.2 \%$, better than TVS. The sensitivity, specificity, PPV, and NPV of SIS in the detection of intrauterine abnormality was $96.2 \%, 71.4 \%, 92.9 \%$ and $83.3 \%$, respectively. In this study, the diagnostic accuracy of SIS in identifying patients with abnormal histopathology was $88.2 \%$.

Conclusion: Saline infusion sonohysterography can be considered to be a valuable tool in the early workup of postmenopausal bleeding as it is an outpatient, lesstime-consuming procedure and noninvasive with no requirement for anesthesia.

Clinical significance: Saline infusion sonohysterography is a sensitive tool and is superior to TVS used alone for evaluation of the uterine cavity. Saline contrast hysterosonography, in combination with HPE if necessary, can become the standard diagnostic procedure in women with postmenopausal bleeding, the gold standard being hysteroscopy.

Keywords: Endometrial polyp, Postmenopausal bleeding, Saline infusion sonohysterography.

Journal of South Asian Federation of Obstetrics and Gynaecology (2020): 10.5005/jp-journals-10006-1765
\end{abstract}

\section{INTRODUCTION}

Postmenopausal bleeding is a serious and not uncommon gynecological problem that needs evaluation to rule out endometrial carcinoma. It is defined as the uterine bleeding occurring for more than 12 months after the last menstrual period of a menopausal women. Studies have indicated the incidence of malignancy in such patients ranging from $1 \%$ to $14 \%$. $^{1}$ Other potential causes of bleeding are cervical cancer, cervicitis, atrophic vaginitis, endometrial atrophy, submucous fibroids, endometrial hyperplasia, and endometrial polyps. ${ }^{2}$

The American College of Obstetricians and Gynecologists has opined that in postmenopausal women with bleeding, when present, "a thin distinct endometrial echo on transvaginal ultrasonography of $4 \mathrm{~mm}$ or less has a risk of malignancy of 1 in 917 and therefore endometrial biopsy is not required". ${ }^{3}$ The most likely diagnosis in such cases is an atrophic endometrium.

Transvaginal sonography (TVS) plays an important role as the initial modality for the evaluation of postmenopausal bleeding. Focal lesions such as polyps and submucous fibroids are underdiagnosed at TVS because of limitations of the doublelayer thickness evaluation. ${ }^{4}$ Sonohysterography is a relatively simple, inexpensive and well-tolerated office procedure. It yields an excellent depiction of the endometrial thickness and it will distinguish focal from global lesions. ${ }^{1}$

In this prospective study, we assessed the diagnostic accuracy of saline infusion sonohysterography (SIS) in detecting uterine pathology in postmenopausal women with bleeding and compared

\begin{abstract}
${ }^{1-3}$ Department of Obstetrics and Gynaecology, Deenanath Mangeshkar Hospital, Pune, Maharashtra, India

Corresponding Author: Akriti Agarwal, Department of Obstetrics and Gynaecology, Deenanath Mangeshkar Hospital, Pune, Maharashtra, India, Phone: +91 9039527107, e-mail: agarwalakriti8@gmail.com

How to cite this article: Gokhale AN, Surve S, Agarwal A. Evaluation of the Efficacy of Saline Infusion Sonohysterography in Patients with Postmenopausal Bleeding. J South Asian Feder Obst Gynae 2020;12(2):79-84.
\end{abstract}

Source of support: Nil

Conflict of interest: None

it with TVS, on the basis of histopathological reports. Histopathology after endometrial biopsy, hysteroscopy, or hysterectomy with tissue sampling would provide a more accurate diagnosis and hence is taken as the standard for this study.

\section{Materials and Methods}

The present prospective observational study was conducted on 34 postmenopausal women presenting with bleeding or spotting per vaginally in the Obstetrics and Gynaecology OPD of Deenanath Mangeshkar Hospital and Research Centre, Pune, Maharashtra, India, and willing to undergo SIS. Criteria for inclusion were the following: all postmenopausal women who were willing to undergo SIS and presenting with bleeding or spotting occurring 
during the first part of the cycle in those receiving sequential hormonal replacement therapy. Uterus $>12$ weeks' size, previous abnormal endometrial biopsy, any cervical pathology on speculum examination, abnormal cervical pap smear or history/evidence suggestive of active pelvic infection were excluded from the study.

Ethical committee approval was obtained prior to start of the study protocol. All SIS were done on an outpatient basis in the gynecology department using a Sonosite Micromax ultrasound machine and endovaginal probe with frequency $5-8 \mathrm{MHz}$ by the same consultant. The patient was counseled and consent was duly obtained for the procedure. Statistical analysis were done using SPSS version 20 .

A detailed history, demographic data, and examination of the patient was noted down. The patient was positioned in the dorsal position on the ultrasonography examination table after emptying bladder. Aseptic precautions were taken at every step of the procedure. After a gentle per vaginal examination, primary screening was done using a transvaginal ultrasound. The perineum and vagina were painted gently using povidone iodine solution. Cusco's speculum was inserted into the vagina and positioned so that the cervix is centrally located. A 6 or 8Fr Foleys catheter was inserted into the cervix and advanced beyond internal os. The balloon of the Foleys catheter was inflated with 2-3 cc of normal saline and tugged to fit against the cervix. The Cusco's speculum was then withdrawn.The vaginal probe was reinserted above the catheter in anteverted uterus and below the catheter in retroverted uterus, to avoid dislodgement. Under sonographic view, 5-10 cc saline was slowly injected into the cavity and the distended cavity was viewed in the mid-sagittal plane which included the entire length of the cervical canal, as a landmark for orientation. The transducer was turned $90^{\circ}$ and the uterus was scanned in the transverse view from the cervix to the fundus, enabling the examiner to construct a mental three-dimensional image of the cavity. The pouch of Douglas was screened to note for the presence or absence of free fluid. Images were recorded for viewing after procedure.

After the procedure, the patient was kept under observation for half an hour to watch for immediate complications such as abdominal cramp, pain, and allergic reactions. A final pathologic diagnosis was made by using the histopathological results obtained after pipelle's biopsy, dilatation and curettage, or hysteroscopic guided biopsy. Abnormal histopathological findings included hyperplasia, polyps, leiomyoma, and adenocarcinoma. Correlating histopathological diagnosis and SIS findings helped to determine accuracy of SIS.

In the normal examination, the uterine cavity was distended symmetrically and the endometrium appeared symmetric and uniformly thick (Fig. 1). The measurement of the endometrial thickness in thin (Fig. 2) and thick (Fig. 3) endometrium on SIS was obtained by adding the thickness of the opposite endometrial linings. Polyps were seen as hemogeneous, smooth hyperechoic masses with well-defined margins (Fig. 4). Leiomyomas were localized and categorized well on SIS as compared to TVS (Fig. 5). Unlike transvaginal sonography, SIS was able to distinguish whether the endometrial thickening was due to a diffuse process or a focal lesion. Endometrial carcinoma appeared as an irregularly thickened endometrium with variable echogenicity and distortion of endometrial-myometrial junction with a poor filling of uterine cavity (Fig. 6)..$^{5}$

\section{Results and Observations}

The tolerance of SIS procedure was excellent and all examinations were completed successfully. In a few patients, some endovaginal reflux of saline was noted during injection. The most common abnormality detected on SIS was thickened endometrium (ET- $4 \mathrm{~mm}$ to $22 \mathrm{~mm}$ ) seen ( 13 cases, $38.2 \%$ ), followed by polyps (11 cases, $32.4 \%$ ), thin endometrium (6 cases, $17.6 \%$ ), submucous fibroids ( 3 cases, $8.8 \%$ ), and undetermined (1 case, $2.9 \%)$. On TVS, 25 patients (73.5\%) had thickened endometrium and 3 patients $(8.8 \%)$ had polyps. Two patients who were detected to have thin endometrium on SIS were actually diagnosed to have thickened endometrium on TVS (Table 1).

We further studied the diagnostic performance and validity of TVS and SIS for 3 main endometrial abnormalities, i.e., endometrial hyperplasia, polyps, and submucous myoma, and our results are tabulated in Tables 2 to 4.The sensitivity and specificity of SIS for diagnosing these lesions are better than those of TVS. Out of the 17 cases of endometrial hyperplasia, 12 were correctly diagnosed on SIS in comparison to 11 diagnosed on TVS. On SIS, 5 cases (3 polyps, 1 thin endometrium, and 1 undetermined) were diagnosed as endometrial hyperplasia on histopathological examination. The sensitivity, specificity, and diagnostic accuracy of SIS vs those of TVS for diagnosing thickened endometrium were $70.6 \%, 94.1 \%$, and $82.3 \%$ vs $64.7 \%, 17.6 \%$, and $41.1 \%$, respectively.

In cases of endometrial polyp, the sensitivity and specificity of SIS was $100 \%$ and $88.5 \%$ and those of TVS was $25 \%$ and $96.2 \%$, respectively. In diagnosing submucous myomas, SIS and TVS had $100 \%$ and $50 \%$ sensitivity, respectively, and $97 \%$ and 96.9\% specificity, respectively. Diagnostic accuracy of SIS vs TVS for endometrial polyp was $91.2 \%$ vs $79.4 \%$ and for submucous myoma was $97 \%$ vs $94.1 \%$. In this study, diagnostic accuracy of SIS in identifying patients with abnormal histopathology was $88.2 \%$, with sensitivity and specificity of $96.2 \%$ and $71.4 \%$, respectively (Table 5). The PPV and NPV of SIS in this study were $92.9 \%$ and $83.3 \%$, respectively.

In the present study, the diagnostic accuracy using Cohen's $\mathrm{K}$ coefficient is 0.715 which is statistically significant with $p$ value $=$ 0.000 .

Pearson's Chi-square test was applied giving a $p$ value $\leq 0.001$ which shows that there is significant association between SIS

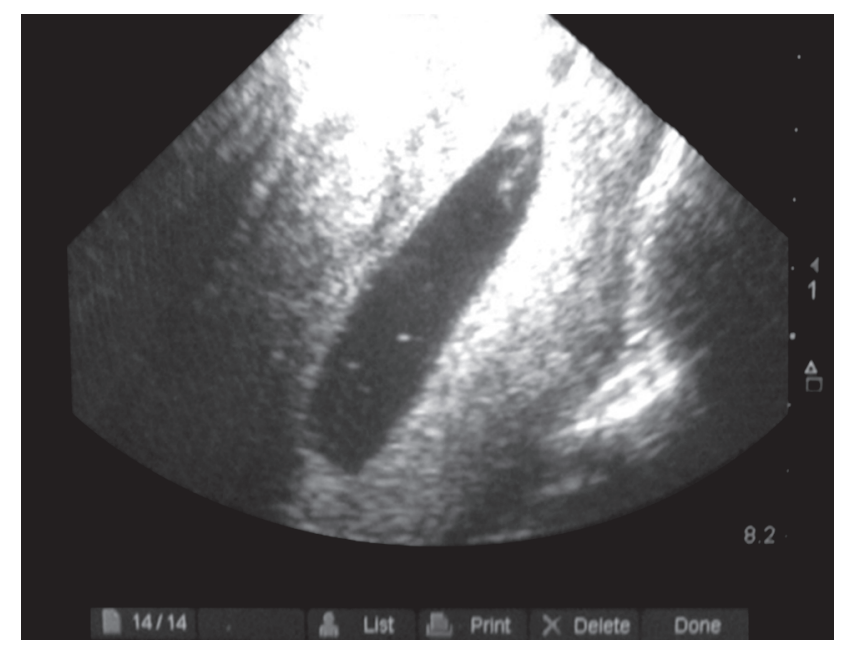

Fig. 1: Normal endometrium 


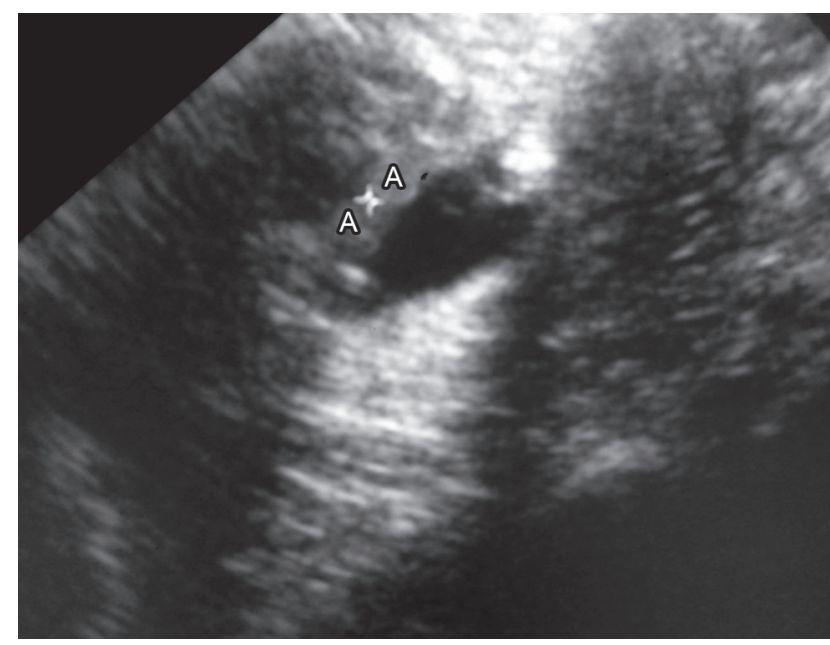

Fig. 2: Thin endometrium

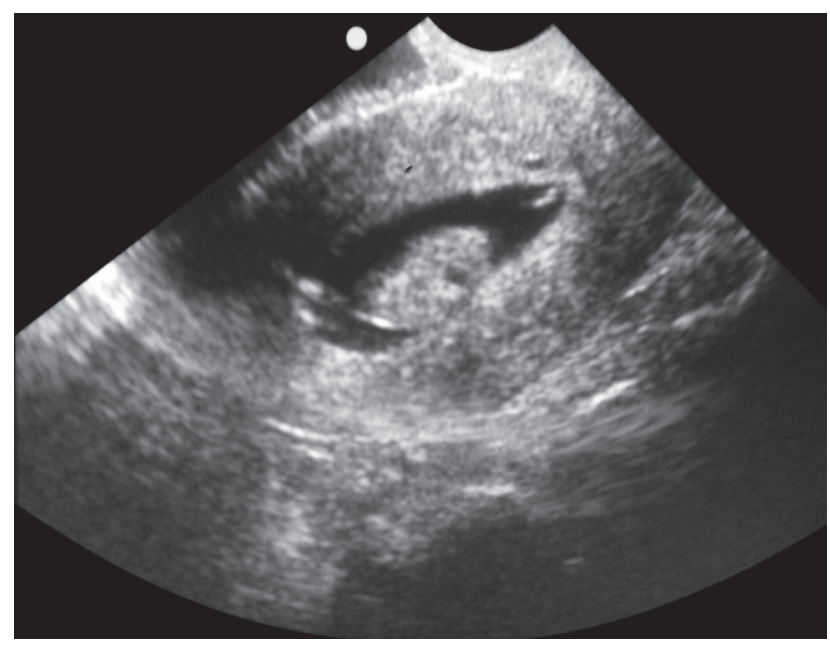

Fig. 4: Sessile endometrial polyp

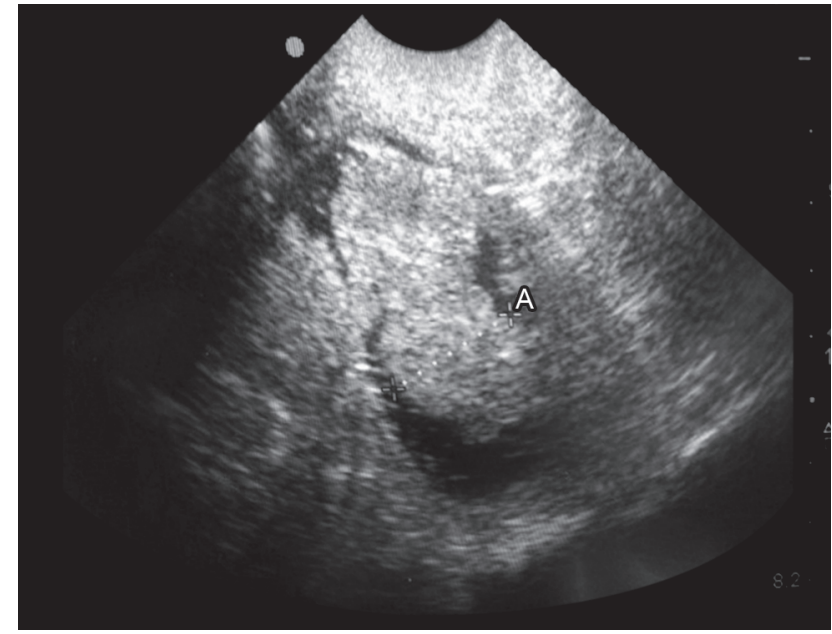

Fig. 6: Malignant endometrial polyp

and histopathological findings (Table 6). Thin endometrium had sensitivity, specificity, and diagnostic accuracy of $71.4 \%, 96.3 \%$, and $91.2 \%$, respectively, on SIS as against that on TVS of $42.9 \%, 96.2 \%$, and $85.3 \%$, respectively.

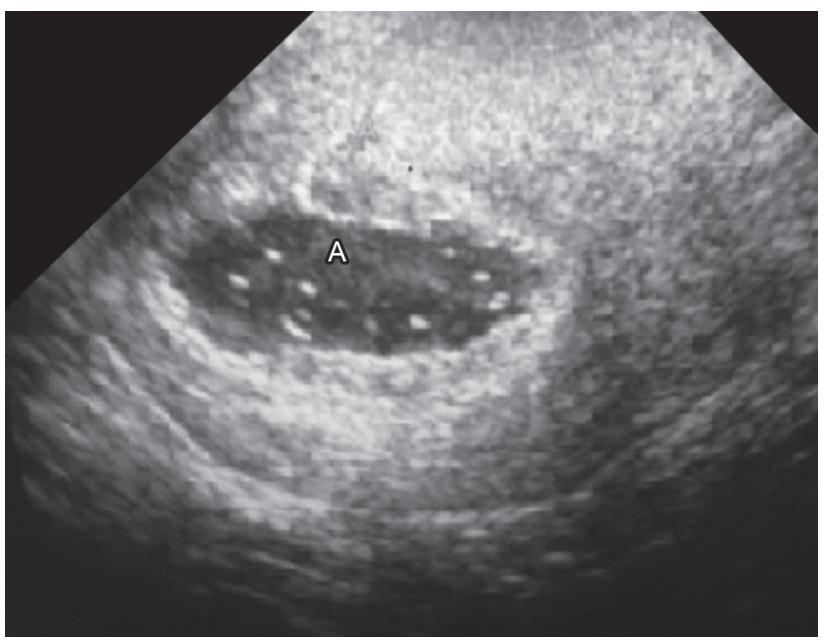

Fig. 3: Thickened endometrium

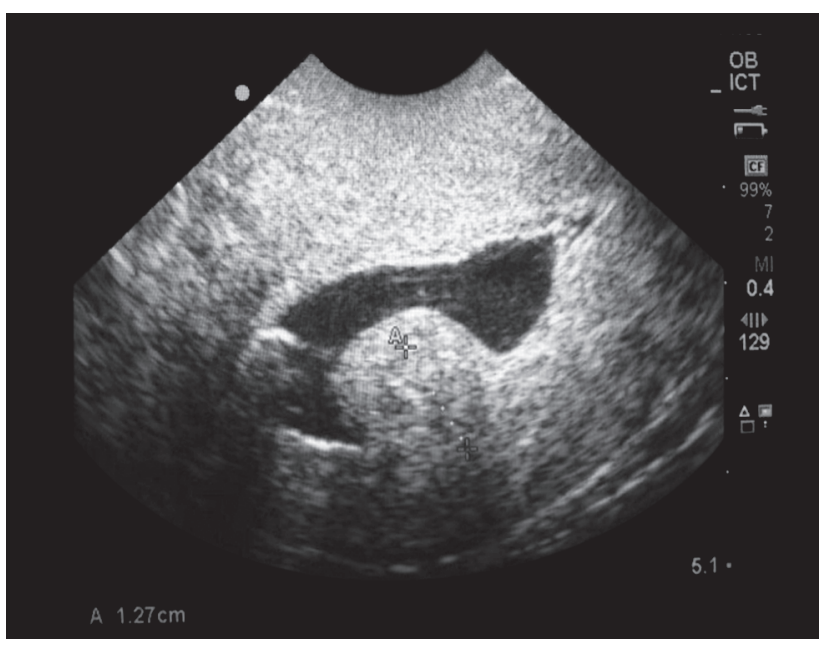

Fig. 5: Submucous myoma

Table 1: SIS and TVS results

\begin{tabular}{lcc}
\hline Diagnosis & $S I S, n(\%)$ & TVS, $n(\%)$ \\
\hline Undetermined & $1(2.9)$ & - \\
Endometrial polyp & $11(32.4)$ & $3(8.8)$ \\
Thickened endometrium & $13(38.2)$ & $25(73.5)$ \\
Thin endometrium & $6(17.6)$ & $4(11.8)$ \\
Submucosal myoma & $3(8.8)$ & $2(5.9)$ \\
Total & $34(100)$ & $34(100)$ \\
\hline
\end{tabular}

Two patients out of three were diagnosed to have malignancy on SIS. One of these had thick irregular endometrium while the other patient had a poor filling of endometrial cavity due to large irregular endometrial polyps on SIS which were suspected to be malignant. Both of these patients had abnormal findings on TVS but were not suspected to be malignant. SIS had $66.7 \%$ sensitivity, $100 \%$ specificity, 100\% PPV, and $93.9 \%$ NPV in diagnosing malignant lesions in our study.

In 31 (91\%) patients, there were no complications or difficulties encountered (Table 7). In 1 (3\%) patient, insertion of catheter was difficult due to partial cervical stenosis. One (3\%) patient had severe cramping pain and required observation and additional analgesics 
Saline Infusion Sonohysterography in Postmenopausal Bleeding

Table 2: Validity of SIS for endometrial hyperplasia, polyp, and submucous myoma

\begin{tabular}{|c|c|c|c|c|c|c|c|c|c|}
\hline \multirow[b]{3}{*}{ Diagnosis } & \multicolumn{9}{|c|}{ Histopathological examination } \\
\hline & \multicolumn{3}{|c|}{ Endometrial hyperplasia, $n$ (\%) } & \multicolumn{3}{|c|}{ Endometrial polyp, $n$ (\%) } & \multicolumn{3}{|c|}{ Submucous myoma, $n$ (\%) } \\
\hline & Present & Absent & Total & Present & Absent & Total & Present & Absent & Total \\
\hline Present & $12(70.6)$ & $1(5.9)$ & $13(38.2)$ & $8(100)$ & $3(11.5)$ & $11(32.4)$ & $2(100)$ & $1(3)$ & $3(5.9)$ \\
\hline Absent & $5(29.4)$ & $16(94.1)$ & $21(61.8)$ & 0 & $23(88.5)$ & $23(67.6)$ & 0 & $31(97)$ & $31(94.1)$ \\
\hline Total & $17(100)$ & $17(100)$ & $34(100)$ & $8(100)$ & $26(100)$ & $34(100)$ & $2(100)$ & $32(100)$ & $34(100)$ \\
\hline
\end{tabular}

Table 3: Validity of TVS for endometrial hyperplasia, polyp, and submucous myoma

\begin{tabular}{|c|c|c|c|c|c|c|c|c|c|}
\hline \multirow{3}{*}{$\begin{array}{l}\text { TVS } \\
\text { Diagnosis }\end{array}$} & \multicolumn{9}{|c|}{ Histopathological examination } \\
\hline & \multicolumn{3}{|c|}{ Endometrial hyperplasia, $n$ (\%) } & \multicolumn{3}{|c|}{ Endometrial polyp, $n(\%)$} & \multicolumn{3}{|c|}{ Submucous myoma, $n$ (\%) } \\
\hline & Present & Absent & Total & Present & Absent & Total & Present & Absent & Total \\
\hline Present & $11(64.7)$ & $14(82.4)$ & $25(73.5)$ & $2(25)$ & $1(3.8)$ & $3(8.8)$ & $1(50)$ & $1(3.2)$ & $2(5.9)$ \\
\hline Absent & $6(35.3)$ & $3(17.6)$ & $9(26.5)$ & $6(75)$ & $25(96.2)$ & $31(91.2)$ & $1(50)$ & $31(96.8)$ & $32(94.1)$ \\
\hline Total & $17(100)$ & $17(100)$ & $34(100)$ & $8(100)$ & $26(100)$ & $34(100)$ & $2(100)$ & $32(100)$ & $34(100)$ \\
\hline
\end{tabular}

Table 4: Diagnostic performance of SIS and TVS in identifying various causes

\begin{tabular}{|c|c|c|c|c|c|c|}
\hline \multirow[b]{2}{*}{ Diagnosis test performance } & \multicolumn{2}{|c|}{ Thickened endometrium } & \multicolumn{2}{|c|}{ Endometrial polyp } & \multicolumn{2}{|c|}{ Submucous myoma } \\
\hline & SIS & TVS & SIS & TVS & SIS & TVS \\
\hline Sensitivity (\%) & 70.6 & 64.7 & 100 & 25 & 100 & 50 \\
\hline Specificity (\%) & 94.1 & 17.6 & 88.5 & 96.2 & 97 & 96.9 \\
\hline PPV (\%) & 92.3 & 44 & 72.7 & 66.7 & 66.7 & 50 \\
\hline NPV (\%) & 76.2 & 33.3 & 100 & 80.6 & 100 & 96.9 \\
\hline Diagnostic accuracy (\%) & 82.3 & 41.1 & 91.2 & 79.4 & 97 & 94.1 \\
\hline
\end{tabular}

Table 5: Performance characteristics of SIS with reference to the histopathology reports

\begin{tabular}{lccc}
\hline & \multicolumn{2}{c}{ Histopathological examination } & \\
\cline { 2 - 3 } SIS & Abnormal & Normal & Total \\
\hline Abnormal & $26(96.2)$ & $2(28.6)$ & $28(82.4)$ \\
Normal & $1(3.8)$ & $5(71.4)$ & $6(17.6)$ \\
Total & $27(100)$ & $7(100)$ & $34(100)$ \\
\hline
\end{tabular}

after procedure. Rest had no pain or very minimal pain and tolerated the procedure well. One (3\%) had poor uterine cavity distension due to large irregular malignant polyps. In our study on SIS, 21 patients underwent dilatation and curettage and 13 underwent endometrial pipelle biopsy as initial histopathological evaluation. The major limitation was that the test required a degree of technical competence, and findings were subjective.

\section{Discussion}

Despite the wide spread use of TVS for the initial evaluation of postmenopausal bleeding, the number of studies in the literature is growing which indicates that TVS has its own limitations in depicting small localized lesions within the endometrium and even a normal thickness endometrium may be seen to represent endometrial hyperplasia. ${ }^{5}$ SIS has been proposed for the diagnosis of intrauterine abnormalities with good results. ${ }^{6}$ SIS was found to be easy to learn, well tolerated by patients, and did not carry any major complications. It was performed in 34 cases of postmenopausal bleeding and its correlation with TVS and histopathological findings was sought to evaluate the efficacy of SIS.
We studied 34 postmenopausal patients with a mean age of $52 \pm 7.4$ years. The presenting complaint was either bleeding or spotting in these patients. None of our patients were on HRT. The mean ages of postmenopausal group studied in Epstein et al. and Bingol et al. studies were $63 \pm 10$ years and $61.6 \pm 9.6$ years, respectively., ${ }^{7,8}$

Of the 34 patients on SIS, the commonest finding was thickened endometrium in $13(38.2 \%)$, endometrial polyps in $11(32.4 \%)$, submucosal myoma in 3 (8.8\%), normal findings in 6 (17.6\%), and uncertain in 1 (2.9\%). In the Ma and Dwivedi study, SIS diagnosed normal endometrium in 40\%, endometrial polyps in 45\%, thickened endometrium in $7.5 \%$, and inconclusive findings in $7.5 \%$ of patients. ${ }^{9}$ The postmenopausal group in the Yildizhan study showed polyps in $32.0 \%$, submucosal fibroids in $24.0 \%$, intramural fibroids in $8.0 \%$, hyperplasia in $8.0 \%$, and normal report in $28.0 \%$ patients. $^{10}$

In this study, abnormal findings on SIS were found in 28 patients $(82.4 \%)$ while the remaining 6 patients (17.6\%) showed no abnormality (thin/scanty endometrium). Similarly studies by Yildizhan et al. and Dwivedi et al. in postmenopausal women showed abnormality in $72 \%$ and $60 \%$ patients, respectively. ${ }^{9,10}$

The sensitivity, specificity, PPV, and NPV of SIS in the detection of intrauterine abnormality in the present study was $96.2 \%, 71.4 \%$, $92.9 \%$, and $83.3 \%$, respectively, while Kazandi et al.'s study showed sensitivity and specificity of SIS being $97 \%, 60 \%, 81 \%$, and $93 \%$, respectively, which was similar to the results of the present study. ${ }^{11}$ While Bingol et al. and Erdem et al. studies showed sensitivity of $89.6 \%$ and $97.7 \%$ and specificity of $77.3 \%$ and $82.4 \%$, respectively. ${ }^{8}$ Diagnostic accuracy of SIS in identifying patients with intrauterine abnormalities was $91.2 \%$ in the present study and was comparable with Kazandi et al. and Bingol et al. studies., 8,11 


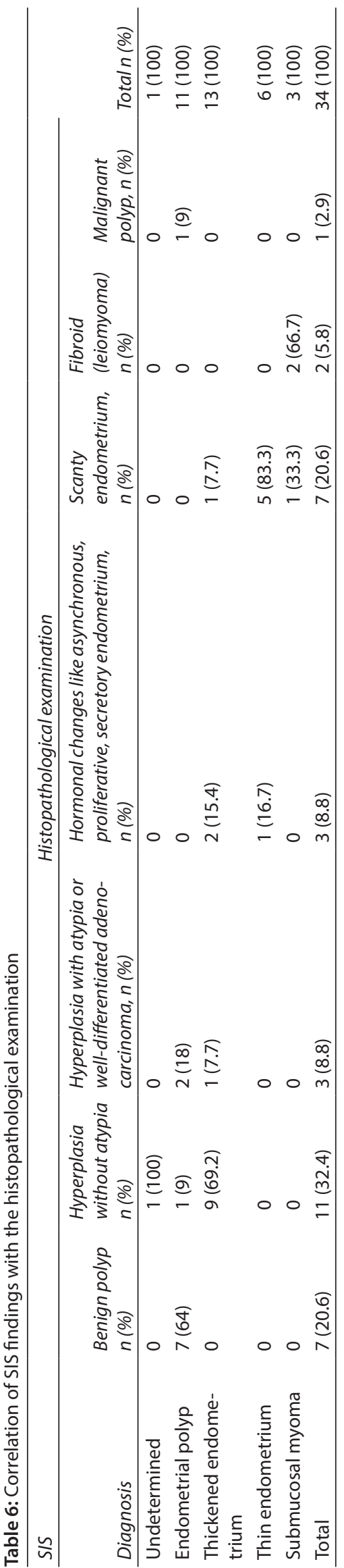

Table 7: The distribution of complications

\begin{tabular}{lcc}
\hline $\begin{array}{l}\text { Complications/ } \\
\text { difficulties }\end{array}$ & No. of cases $(n)$ & Percentage of cases \\
\hline None & 31 & 91 \\
$\begin{array}{l}\text { Difficult insertion } \\
\text { Poor uterine cavity }\end{array}$ & 1 & 3 \\
distension & 1 & 3 \\
$\begin{array}{l}\text { Severe cramping } \\
\text { pain }\end{array}$ & 1 & 3 \\
Total & 34 & 100 \\
\hline
\end{tabular}

Studies done by Yildizhan et al., Erdem et al. and the present study showed higher specificity of SIS for diagnosing endometrial polyps and submucosal myomas but higher sensitivity for diagnosing polyps in Erdem et al. and higher sensitivity of diagnosing submucous myomas in Aslam et al. study were similar to our study. ${ }^{10,12,13}$ High specificity of diagnosing thickened endometrium in the present study was similar to Aslam et al. study but sensitivity was higher in Aslam et al. as compared to the present study ${ }^{13}$ as depicted in Table 8.

The accuracy of SIS in the diagnosis 0 intrauterine focal lesions such as polyp and submucosal myoma was higher than on TVS in the present study. Yildizhan et al. found sensitivity and specificity of TVS in detecting endometrial polyps as $65.2 \%$ and $87.9 \%$, respectively, when compared with $91.3 \%$ and $93.1 \%$ for SIS, respectively, and the sensitivity and specificity of TVS in detecting submucous fibroids were $95.8 \%$ and $95.0 \%$, respectively, vs $91.6 \%$ and $98.7 \%$, respectively, for SIS. ${ }^{10}$ Thus it can be concluded that SIS is a satisfactory method for diagnosing intrauterine pathologies. It is easy, cost-effective, and improves the diagnostic utility of TVS.

SIS was superior to TVS in discriminating benign and malignant endometrium. Distension difficulties and irregular endometrial lining seen in SIS lead to the suspicion of malignancy in the present study in 2 cases (5.8\%) and these findings are in agreement with Epstein et al. study. ${ }^{7}$ We did not encounter any major complication related to SIS. Complications of SIS include bleeding, infection, perforation (due to instrumentation), and theoretical risk of spreading of carcinoma. ${ }^{13}$ Most important limitation of our study was the small sample size. More studies need to be done with large sample sizes in future.

\section{CONCLUSION}

Our results have substantiated that SIS is a better tool as compared to TVS for the assessment of endometrial intra-cavity lesions. It accurately differentiates between focal and diffuse endometrial lesions. It is an OPD-based, noninvasive, less-time-consuming procedure with no requirement for anesthesia. It has a good sensitivity and specificity and hence can help to avoid unnecessary hysteroscopy for the diagnosis of intrauterine lesions. We recommend that saline contrast sonohysterography should be used as an initial investigation in cases of postmenopausal bleeding, the gold standard being hysteroscopy.

\section{Clinical Significance}

SIS is a sensitive tool and is superior to TVS used alone for the evaluation of the uterine cavity. We also conclude that saline contrast hysterosonography, in combination with HPE if necessary, can become the standard diagnostic procedure in 
Table 8: Comparison of sensitivity and specificity of SIS for thickened endometrium, polyp, and submucosal myoma with various studies

\begin{tabular}{|c|c|c|c|c|c|c|}
\hline \multirow[b]{2}{*}{ Various studies } & \multicolumn{2}{|c|}{ Hyperplasia } & \multicolumn{2}{|c|}{ Polyp } & \multicolumn{2}{|c|}{ Submucosal myoma } \\
\hline & Sensitivity & Specificity & Sensitivity & Specificity & Sensitivity & Specificity \\
\hline Yildizhan et al. $^{10}$ & - & - & 91.3 & 93.1 & 91.6 & 98.7 \\
\hline Erdem et al. ${ }^{12}$ & - & - & 100 & 91.8 & 95 & 100 \\
\hline Aslam et al. ${ }^{13}$ & 93.7 & 91.2 & 90 & 98 & 100 & 100 \\
\hline Present study & 70.6 & 94.1 & 100 & 88.5 & 100 & 97 \\
\hline
\end{tabular}

women with postmenopausal bleeding, the gold standard being hysteroscopy.

\section{ACKnOWLedgment}

We sincerely thank Deenanath Mangeshkar Hospital research consultant Dr Gauri Oka and research assistant Mrs Prachi Avalaskar. We are thankful to the ethics committee of Deenanath Mangeshkar Hospital and Research Centre for permitting us to conduct this study.

\section{References}

1. Goldstein SR. Sonography in postmenopausal bleeding. JUltarsound Med 2012;31(2):333-336. DOI: 10.7863/jum.2012.31.2.333.

2. Chuong CJ, Brenner PF. Management of abnormal uterine bleeding. Am J ObstetGynecol 1996;175(3 Pt 2):787-792. DOI: 10.1016/s00029378(96)80086-x.

3. American College of Obstetricians and Gynecologists. ACOG committee opinion no. 426: the role of transvaginal ultrasonography in the evaluation of postmenopausal bleeding. Obstet Gynecol 2009;113(2, Part 1):462-464. DOI: 10.1097/AOG.0b013e31819930cc.

4. Davis PC, Neill O, Yoder MJ, et al. Sonohysterographic findings of endometrial and subendometrial conditions. Radiographics 2002;22(4):803-816. DOI: 10.1148/radiographics.22.4.g02jl21803.

5. Bree RL. Ultrasound of the endometrium: facts, controversies, and future trends. Abdom Imaging 1997;22(6):557-568. DOI: 10.1007/ s002619900265.

6. Schwärzler P, Concin H, Bösch H, et al. An evaluation of sonohysterography and diagnostic hysteroscopy for the assessment of intrauterine pathology. Ultrasound Obstet Gynecol 1998;11(5): 337-342. DOI: 10.1046/j.1469-0705.1998.11050337.x.
7. Epstein E, Ramirez A, Skoog L, et al. Transvaginal sonography, saline contrast sonohysterography and hysteroscopy for the investigation of women with postmenopausal bleeding and endometrium $>5 \mathrm{~mm}$. Ultrasound Obstet Gynecol 2001;18(2):157-162. DOI: 10.1046/j.14690705.2001.00472.x.

8. Bingol B, Gunenc MZ, Gedikbasi A, et al. Comparison of diagnostic accuracy of saline infusion sonohysterography, transvaginal sonography and hysteroscopy in postmenopausal bleeding. J Obstet Gynecol 2011;284(1):111-117. DOI: 10.1007/s00404-0101604-0.

9. Ma K, Dwivedi R. Saline infusion sonography in women presenting with postmenopausal bleeding: positive predictive value and patient experience. 24th World Cong Ultrasound Obstet Gynecol 2014;44(S1):14-17.

10. Yildizhan B, Yildizhan R, Ozkesici B, et al. Transvaginal ultrasonography and saline infusion sonohysterography for the detection of intrauterine lesions in post menopausal women with bleeding. J Int Med Res 2008;36(6):1205-1213. DOI: 10.1177/147323000803600606.

11. Kazandi M, Akşehirli S, Cirpan T, et al. Transvaginal sonography combined with saline contrast sonohysterography to evaluate the uterine cavity in patients with abnormal uterine bleeding and postmenopausal endometrium more than $5 \mathrm{~mm}$. Eur J Gynecol onco 2003;24(2):185-190.

12. Erdem M, Bilgin U, Bozkurt N. Comparison of transvaginal ultrasonography and saline infusion sonohysterography in evaluating the endometrial cavity in pre- and postmenopausal women with abnormal uterine bleeding. Menopause 2007;14(5):846-852. DOI: 10.1097/gme.0b013e3180333a6b.

13. Aslam M, ljaz L, Tariq S, et al. Comparison of transvaginal sonography and saline contrast sonohysterography in womenwith abnormal uterine bleeding: correlation with hysteroscopy and histopathology. Int J Health Sci, Qassim Univer 2007;1(1):17-24. 